\title{
The role of GLP-1 in the postprandial effects of acarbose in type 2 diabetes
}

\author{
Niels B Dalsgaard', Lærke S Gasbjerg ${ }^{1,2}$, Laura S Hansen', Nina L Hansen', Signe Stensen', Bolette Hartmannn ${ }^{2,3}$, \\ Jens F Rehfeld ${ }^{4}$, Jens J Holst ${ }^{2,3}$, Tina Vilsbø|l',5,6 and Filip K Knop ${ }^{113,5,6}$
}

${ }^{1}$ Center for Clinical Metabolic Research, Gentofte Hospital, University of Copenhagen, Hellerup, Denmark, ${ }^{2}$ Department of Biomedical Sciences, Faculty of Health and Medical Sciences, University of Copenhagen, Copenhagen, Denmark, ${ }^{3}$ Novo Nordisk Foundation Center for Basic Metabolic Research, Faculty of Health and Medical Sciences, University of Copenhagen, Copenhagen, Denmark, ${ }^{4}$ Department of Clinical Biochemistry, Rigshospitalet, University of Copenhagen,

Copenhagen, Denmark, ${ }^{5}$ Department of Clinical Medicine, Faculty of Health and Medical Sciences, University of Copenhagen, Copenhagen, Denmark, and ${ }^{6}$ Steno Diabetes Center Copenhagen, Gentofte, Denmark

Correspondence should be addressed to F K Knop Email

filip.krag.knop.01@regionh.dk

\begin{abstract}
Aims: The alpha-glucosidase inhibitor acarbose is believed to reduce plasma glucose by delaying hydrolysis of carbohydrates. Acarbose-induced transfer of carbohydrates to the distal parts of the intestine increases circulating glucagon-like peptide 1 (GLP-1). Using the GLP-1 receptor antagonist exendin(9-39) $\mathrm{NH}_{2}$, we investigated the effect of acarbose-induced GLP-1 secretion on postprandial glucose metabolism in patients with type 2 diabetes.

Methods: In a double-blinded, placebo-controlled, randomized, crossover study, 15 participants with metformin-treated type 2 diabetes (age: $57-85$ years, $\mathrm{HbA} 1 \mathrm{c}: 40-74 \mathrm{mmol} / \mathrm{mol}$ ) were subjected to two 14-day treatment periods with acarbose or placebo, respectively, separated by a 6-week wash-out period. At the end of each period, two randomized 4-h liquid mixed meal tests with concomitant infusion of exendin(9-39) $\mathrm{NH}_{2}$ and saline, respectively, were performed. Results: Compared to placebo, acarbose increased postprandial GLP-1 concentrations and decreased postprandial glucose. We observed no absolute difference in the exendin(9-39) $\mathrm{NH}_{2}$-induced increase in postprandial glucose excursions between placebo and acarbose periods, but relatively, postprandial glucose was increased by $119 \pm 116 \%$ (mean \pm S.D.) during exendin(9-39) $\mathrm{NH}_{2}$ infusion in the acarbose period vs a $39 \pm 27 \%$ increase during the placebo period $(P=0.0163)$.

Conclusions: We confirm that acarbose treatment stimulates postprandial GLP-1 secretion in patients with type 2 diabetes. Using exendin(9-39) $\mathrm{NH}_{2}$, we did not see an impact of acarbose-induced GLP-1 secretion on absolute measures of postprandial glucose tolerance, but relatively, the effect of exendin(9-39) $\mathrm{NH}_{2}$ was most pronounced during acarbose treatment.
\end{abstract}

\section{Introduction}

The gastrointestinal tract contributes to the regulation of glucose metabolism by several mechanisms including nutrient-induced secretion of the incretin hormones, glucagon-like peptide 1 (GLP-1) and glucose-dependent insulinotropic polypeptide (GIP) (1). These hormones are released postprandially from enteroendocrine cells; GIP from K cells with high density in the proximal small intestine, and GLP-1 from L cells with higher density more (c) 2021 European Society of Endocrinology Printed in Great Britain distally in the gut (2). Both hormones are insulinotropic and contribute importantly to normal postprandial glucose tolerance (3). In addition to its insulinotropic effect, GLP-1 potentiates glucose-induced suppression of glucagon (4), decelerates gastric emptying and reduces appetite and food intake (5). These effects are currently being utilized in the management of type 2 diabetes by treatment with GLP-1 receptor agonists and oral

Published by Bioscientifica Ltd. 
dipeptidyl peptidase 4 (DPP-4) inhibitors, respectively. It has been speculated that stimulation of GLP-1 secretion might represent a superior alternative to existing GLP1-based treatments, and strategies promoting GLP-1 secretion without increasing caloric intake are warranted (6). Pharmacological inhibition of the oligosaccharide, trisaccharide and disaccharide-hydrolizing intestinal enzyme alpha-glucosidase, delays carbohydrate digestion in the proximal gut causing a transfer of carbohydrates to the distal and L cell-rich part of the small intestine (7). Alpha-glucosidase inhibitors represent well-known oral antidiabetic agents used for the treatment of type 2 diabetes. The most widely used compound, acarbose, also inhibits salivary and pancreatic amylase, and it is believed that acarbose primarily lowers postprandial glucose excursions by delaying the rate of carbohydrate digestion and absorption (7); however, mechanistic studies establishing the precise glucose-lowering mode of action of acarbose are lacking. Acarbose treatment is recognized for increasing circulating concentrations of several gut hormones in the postprandial state including GLP-1 $(8,9,10,11,12)$, cholecystokinin (CCK) and the satiety-promoting peptide tyrosine tyrosine (PYY) while decreasing postprandial GIP, insulin and ghrelin levels $(11,12,13)$. Acarbose, thus, seems to represent an indirect non-nutritional GLP-1 secretagogue that work by promoting monosaccharide absorption in the distal gut (11). We used the specific GLP-1 receptor antagonist exendin(9-39) $\mathrm{NH}_{2}$ to investigate and quantify the potential postprandial effects of GLP-1 released as a result of acarbose treatment in patients with type 2 diabetes.

\section{Research design and methods}

The study was performed at Center for Clinical Metabolic Research, Gentofte Hospital, University of Copenhagen, Hellerup, Denmark, after approval of the Ethics Committee of the Capital Region of Denmark (record no. $\mathrm{H}-17007893)$. The study was registered at ClinicalTrials. gov (ID: NCT03241303) and the Danish Data Protection Agency (local no. HGH-2018-041, I-Suite no. 6.802).

\section{Participants}

Inclusion criteria were diagnosis of type 2 diabetes at least 3 months prior to inclusion, metformin treatment, age $>18$ years and BMI between 23 and $35 \mathrm{~kg} / \mathrm{m}^{2}$. Exclusion criteria included acute or chronic illnesses including known hepatobiliary disorders, alanine aminotransferase
$>2$ times normal values, gastrointestinal disease, reduced kidney function (estimated glomerular filtration rate $<60 \mathrm{~mL} / \mathrm{min} / 1.73 \mathrm{~m}^{2}$ ), active/recent malignant disease, pregnancy, thyroid disease, use of medication that could not be paused for $12 \mathrm{~h}$ alongside use of glucose-lowering drugs other than metformin and intake of antibiotics within 2 months prior to inclusion.

\section{Peptides and study drugs}

Oral acarbose Glucobay $^{\circledR}$, Bayer Pharma AG, Berlin, Germany) or matching placebo tablets $(50 \mathrm{mg})$ were administered as study drugs. Exendin(9-39) $\mathrm{NH}_{2}$ (catalog number H-8740, Bachem, Bubendorf, Switzerland) was demonstrated to be identical to the natural peptides by HPLC, mass and sequence analysis with a purity of $97 \%$. Exendin(9-39) $\mathrm{NH}_{2}$ was formulated for infusion by the Central Pharmacy of the Capital Region of Denmark, Herlev, Denmark, using 1\% human albumin (CSL Behring 5\%, infusion fluid, $50 \mathrm{~g} / \mathrm{L}$, CSL Behring GmbH, Marburg, Germany) and sterilized water, with subsequent sterile filtration and testing for endotoxins and microbiological contamination before experimental use. After formulation, vials with exendin(9-39) $\mathrm{NH}_{2}$ were kept at $-20^{\circ} \mathrm{C}$ under sterile condition until use. On the study days, vials with the required amount of exendin(9-39) $\mathrm{NH}_{2}$ were thawed and diluted in sterile isotonic saline $(9 \mathrm{mg} / \mathrm{mL}, \mathrm{B}$. Braun, Meksungen, Germany) with $0.5 \%$ human albumin in a total volume of $250 \mathrm{~mL}$ before infusion. For placebo infusions $250 \mathrm{~mL}$ of isotonic saline with $0.5 \%$ human albumin were used.

\section{Study design}

The study was designed as a randomized, double-blinded, placebo-controlled, crossover study. For each study participant, the study consisted of two 14-day treatment periods with double-blinded administration of either placebo or acarbose in addition to their usual metformin doses, separated by a wash-out period of 6 weeks. Before each treatment period, study participants received the tablets (placebo or acarbose) and an uptitration schedule (with uptitration 2 days prior to the first experimental day to a maximum dose of three tablets of placebo or 100 $\mathrm{mg}$ acarbose at the start of main meals). Otherwise, the study participants were instructed to continue their usual lifestyle and diet. In the end of each treatment period, two liquid mixed meal tests separated by one full day and with administration of either acarbose or placebo depending on the treatment period were performed concomitantly 
with either continuous i.v. infusion of isotonic saline (placebo) or exendin(9-39) $\mathrm{NH}_{2}$ in a double-blinded manner. The primary endpoint was difference between the acarbose-induced change in postprandial plasma glucose excursions observed with and without blockade of GLP-1 receptor signaling.

\section{Experimental procedures}

The study participants arrived at the laboratory after an overnight 10-h fast (including water, coffee, medicine and use of tobacco). They had been instructed not to perform strenuous physical activity or to consume alcohol for $24 \mathrm{~h}$ before each study day. Two cannulas were inserted into the cubital veins of both arms for collection of blood samples and infusions, respectively (the forearm used for blood sampling was wrapped in a heating pad $\left(-45^{\circ} \mathrm{C}\right)$ for arterialization of venous blood). Afterwards, the participants rested $30 \mathrm{~min}$ before start of the infusions. At time $-20 \mathrm{~min}$, the infusion of exendin(9-39) $\mathrm{NH}_{2}(1000$ $\mathrm{pmol} / \mathrm{kg}$ of body weight/min) or isotonic saline was started (depending on randomization schedule). At time $0 \mathrm{~min}$, the infusion rate was lowered to $450 \mathrm{pmol} / \mathrm{kg} / \mathrm{min}$. From time $0 \mathrm{~min}$ to $5 \mathrm{~min}$, the patient ingested a liquid mixed meal (200 mL, 1260 kJ (36.8 g carbohydrate, $11.6 \mathrm{~g}$ protein and $12.0 \mathrm{~g}$ of lipid); Nutricia, Danone, Denmark) to which was added $100 \mathrm{mg}$ of acarbose or placebo powder as well as $100 \mathrm{~mL}$ of water with dissolved paracetamol (1500 mg) (Pinex ${ }^{\circledR}$, Actavis, Dublin, Ireland) for indirect assessment of gastric emptying.

\section{Data collection and laboratory methods}

Blood samples were collected at time -30, -15 and 0 min before and at time 15, 30, 45, 60, 75, 90, 120, 150, 180, 210 and $240 \mathrm{~min}$ after the start of infusion. For bedside measurements of plasma glucose, blood was sampled into sodium-fluoride tubes, centrifuged immediately (at room temperature and $7400 \boldsymbol{g}$ for $30 \mathrm{~s}$ ) and analyzed on a glucose analyzer (YSI 2900D STAT glucose analyzer, Xylem Inc., Yellow Springs, OH, USA). For the analysis of plasma concentrations of GLP-1, GIP, glucagon, PYY, neurotensin, CCK and gastrin, blood was collected in chilled tubes (on ice) containing EDTA together with a specific DPP-4 inhibitor (final concentration $0.01 \mathrm{mmol} / \mathrm{L}$ valine-pyrrolidide) and a serine protease inhibitor (500 $\mathrm{KIE} / \mathrm{mL}$ aprotinin). For the analysis of serum insulin and C-peptide concentrations, blood was sampled in plain tubes and left for $10 \mathrm{~min}$ at room temperature for coagulation. For analysis of plasma paracetamol concentrations, blood was sampled in tubes containing lithium-heparin. All tubes were then centrifuged for 15 min at $2000 \boldsymbol{g}$ and $4^{\circ} \mathrm{C}$, after which they were stored at $-20^{\circ} \mathrm{C}$ until analysis. At time $-60,0,30,55,75,105,135$, 180, 210 and $240 \mathrm{~min}$, the gallbladder was measured ultrasonographically (LOGIQ, GE Healthcare) in three dimensions (height $\times$ width $\times$ length) for determination of gallbladder volume by the ellipsoid method (14). At time -60, -15, 15, 30, 55, 90, 150, 210 and $240 \mathrm{~min}$, the study participants rated hunger, satiety, fullness, prospective food consumption, comfort, nausea and thirst on $100 \mathrm{~mm}$ visual analog scales (VAS). At time $240 \mathrm{~min}$, the study participants received a standardized meal consisting of pasta Bolognese (50 energy (E)\% carbohydrate, $37 \mathrm{E} \%$ fat, $13 \mathrm{E} \%$ protein) served together with $500 \mathrm{~mL}$ of water ad libitum, and were instructed to eat until they felt comfortably full. The food was weighed before and after the meal, and the difference in weight was used to calculate the total energy intake. Serum insulin and C-peptide were measured with twosided electrochemiluminescence assays (Roche/Hitachi Modular Analytics; Roche Diagnostic). Total GLP-1 (15), total GIP (16), PYY (17), neurotensin (18), exendin(9-39)$\mathrm{NH}_{2}$ (19), CCK (20) and gastrin (21) were measured in plasma by radioimmunoassays as previously described. Plasma glucagon was measured by ELISA (cat no. 10-127101; Mercodia, Uppsala, Sweden).

\section{Statistical analyses and calculations}

Based on an S.D. of $661 \mathrm{mmol} / \mathrm{L} \times$ min of plasma glucose excursions during the liquid mixed meal test (assessed by area under curve (AUC) for plasma glucose) obtained from a previous study investigating the glucose-lowering effect of metformin-induced GLP-1 secretion using similar methodology (22), an estimated minimal relevant difference (MIREDIF) of $25 \%$, a power of $80 \%$ and a level of statistical significance of $5 \%$, we calculated the required number of participants $(n)$ using the formula, $n=\left(Z_{\alpha}+Z_{\beta}\right)^{2} \times$ s.D. ${ }^{2} /$ MIREDIF $^{2}$, where $Z_{\alpha}$ and $Z_{\beta}$ are standardized deviations corresponding to the selected significance levels, $Z_{\alpha}=1.96$ and $\mathrm{Z}_{\beta}=1.28$. According to this calculation, 14 study participants had to be included to detect a minimal difference of $25 \%$ in AUC for plasma glucose with and without blockade of GLP-1 signaling by exendin(9-39) $\mathrm{NH}_{2}$. To ensure power of the primary endpoint and reduce the likelihood of statistical type II errors regarding secondary endpoints, 15 participants were included. We applied repeated measures ANOVA (rmANOVA) with GreenhouseGeisser correction and Tukey multiple comparison test for 
significance of changes and differences between endpoints. Statistical analyses were performed with GraphPad Prism 8.1.1 (GraphPad Software). A two-sided $P$ value of $<0.05$ was used as significance level. Results are reported as mean \pm S.D. unless otherwise stated. Calculation of AUC was based on the trapezoidal rule. As our objective was to examine postprandial effects of acarbose, baseline-subtracted AUCs (bsAUCs), which describe meal-induced changes independently of potential baseline differences caused by acarbose and exendin(9-39) $\mathrm{NH}_{2}$ infusion, are reported if nothing else is stated. GLP-1-mediated effects on bsAUC for plasma glucose were calculated in absolute terms with and without exendin(9-39) $\mathrm{NH}_{2}$ (differences in bsAUC $C_{\text {glucose }}$ for placebo treatment period compared to acarbose treatment period), and relative terms (exendin $(9-39) \mathrm{NH}_{2}$-induced differences relative to placebo infusions) and, for each data set, compared using paired $t$-tests. C-peptide:glucose ratios were calculated for evaluation of beta cell sensitivity to glucose. Gastric emptying was evaluated by the use of the paracetamol absorption method (23).

\section{Results}

\section{Study participants}

Two female and thirteen male study participants with metformin-treated type 2 diabetes (Table 1) were included after a screening visit. Written informed consent was obtained from all study participants before inclusion. In general, study participants reported increased flatulence in the acarbose treatment period; otherwise no side effects were reported. All participants completed the intervention periods, but due to poor ultrasonographic projection of the gallbladder, three participants were not included in the gallbladder volume analysis.

\section{Exendin(9-39) $\mathrm{NH}_{2}$ levels}

During exendin(9-39) $\mathrm{NH}_{2}$ infusions, similar mean plasma exendin $(9-39) \mathrm{NH}_{2}$ levels were achieved following placebo treatment and acarbose treament $(162 \pm 23$ vs $169 \pm 23$ nmol/L, $P=0.4082$ ) (Fig. 1).

\section{Glucose}

No difference was observed in fasting plasma glucose levels measured before each infusion $(P=0.1335)$ (Fig. $2 \mathrm{~A}$ and Table 2). In the placebo period, during the liquid meal test with saline infusion, plasma glucose
Table 1 Baseline characteristics of study participants. Data are shown in median with range in parenthesis unless otherwise indicated.

\begin{tabular}{|c|c|}
\hline Variable (unit) & Values \\
\hline Age (years) & $71(57-85)$ \\
\hline Male/female $(n / n)$ & $13 / 2$ \\
\hline Height (m) & $1.78(1.53-1.85)$ \\
\hline Weight (kg) & $87.6(66.3-111)$ \\
\hline $\mathrm{BMI}\left(\mathrm{kg} / \mathrm{m}^{2}\right)$ & $29.7(23.6-34.6)$ \\
\hline Body fat $(\%)$ & $35.4(24.6-45.1)$ \\
\hline Fasting plasma glucose (mmol/L) & $7.8(6.6-11.6)$ \\
\hline $\mathrm{HbA}_{1 \mathrm{c}}(\%)$ & $6.5(5.8-11.6)$ \\
\hline $\mathrm{HbA}_{1 \mathrm{c}}(\mathrm{mmol} / \mathrm{mol})$ & $48(40-74)$ \\
\hline Systolic blood pressure (mmHg) & $136(111-160)$ \\
\hline Diastolic blood pressure (mmHg) & $77(36-89)$ \\
\hline Heart rate $(\mathrm{bpm})$ & $61(55-87)$ \\
\hline HOMA-IR & $2.9(0.64-9.7)$ \\
\hline
\end{tabular}

bpm, beats per minute.

concentrations increased to a mean maximum of $12 \pm 2.1$ $\mathrm{mmol} / \mathrm{L}$ at time $87 \pm 20 \mathrm{~min}$ resulting in a bsAUC of $470 \pm 128 \mathrm{mmol} / \mathrm{L} \times$ min. During exendin $(9-39) \mathrm{NH}_{2}$ infusion, postprandial plasma glucose levels increased to a $16 \pm 5.6 \%$ higher mean peak value $(14 \pm 2.4 \mathrm{mmol} / \mathrm{L}$, $P<0.0001$, compared to saline) resulting in a $39 \pm 27 \%$ greater bsAUC ( $P<0.0001$ compared to saline) (Fig. 2A, B

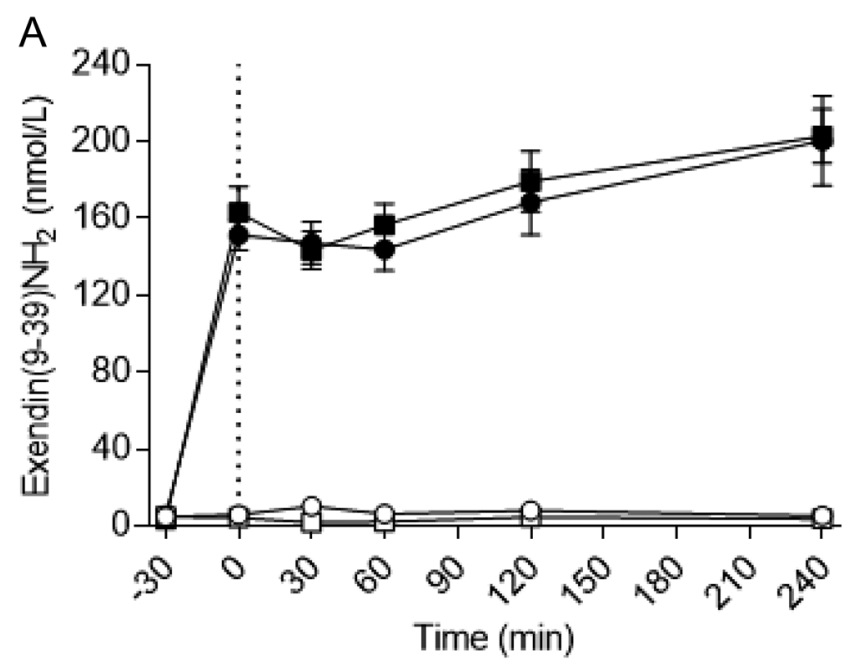

\section{Figure 1}

Exendin(9-39) $\mathrm{NH}_{2}$ levels. Plasma exendin(9-39) $\mathrm{NH}_{2}$ (A) levels in 15 patients with type 2 diabetes during four liquid mixed meal tests (initiated at time 0 , dotted line) with continuous i.v. infusion of exendin(9-39) $\mathrm{NH}_{2}$ (closed symbols) and saline (open symbols), respectively, performed after 14-day treatment periods with placebo (circles) and acarbose (squares). Data are presented as mean \pm S.E.M. 

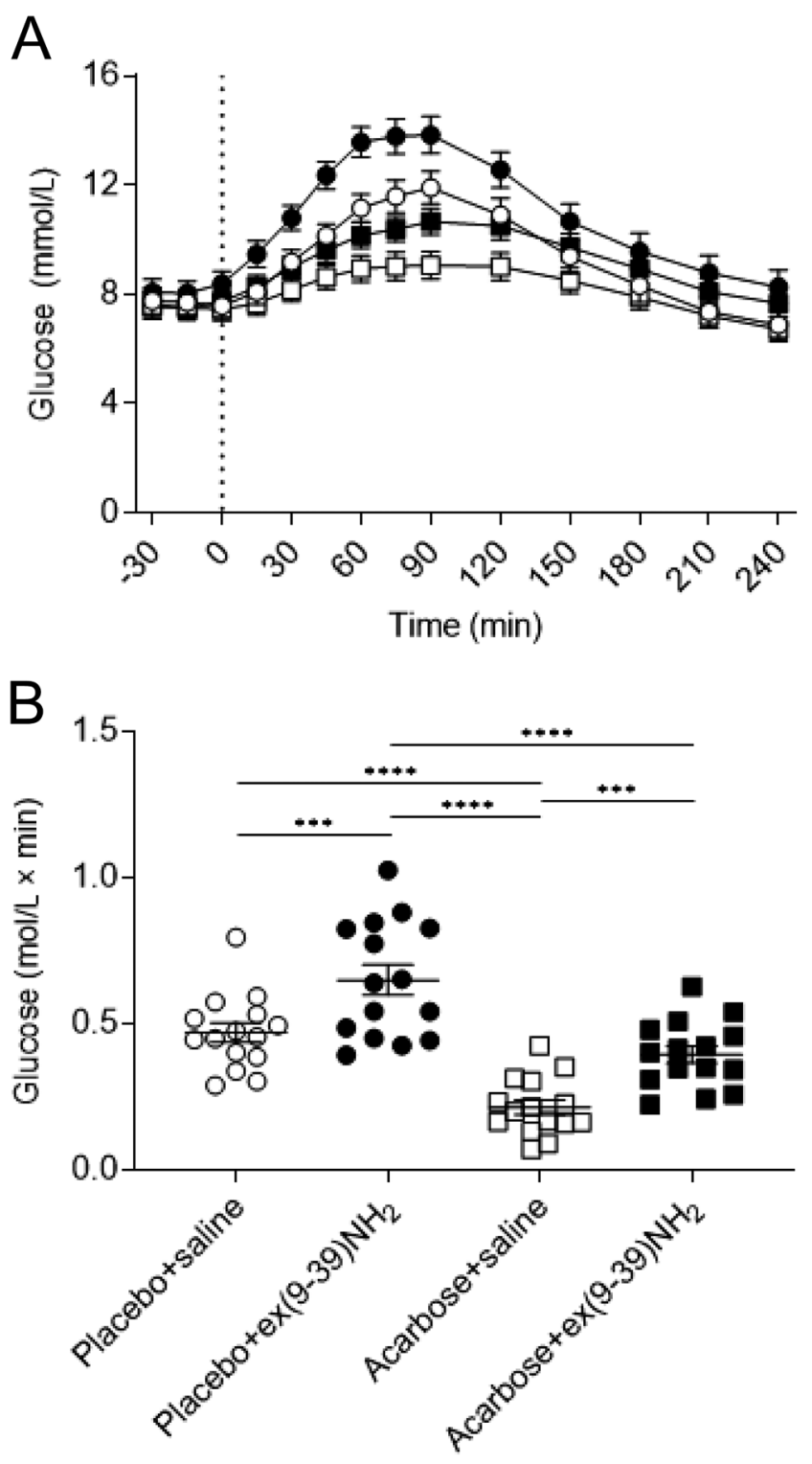

Figure 2

Glucose. Plasma glucose levels (A) and corresponding bsAUC (time 0-240 min) (B) during four liquid mixed meal tests (initiated at time 0 , dotted line) with continuous i.v. infusion of exendin(9-39) $\mathrm{NH}_{2}$ (closed symbols) and saline (open symbols), respectively, performed after 14-day treatment periods with placebo (circles) and acarbose (squares). Data were compared by rmANOVA with Greenhouse-Geisser correction and Tukey multiple comparison. Significant differences for the post hoc analyses are marked with asterisks: $* \star * P<0.001, * \star * * P<$ 0.0001. Data are presented as mean \pm S.E.M. $\operatorname{ex}(9-39) \mathrm{NH}_{2}$, exendin(9-39) $\mathrm{NH}_{2}$.

and Table 2). During the acarbose treatment period, the postprandial plasma glucose peak was $17 \pm 10 \%$ higher during exendin(9-39) $\mathrm{NH}_{2}$ infusion compared to saline.
Furthermore, exendin(9-39) $\mathrm{NH}_{2}$ infusion resulted in higher mean bsAUC compared to saline (119 $\pm 116 \%$, $P<0.0001$ ) (Fig. 2B and Table 2). No absolute difference was seen in exendin(9-39) $\mathrm{NH}_{2}$-induced bsAUC increase between placebo and acarbose treatment, but relatively, the increase in bsAUC of plasma glucose (i.e. the impairment of glucose tolerance) during exendin(9-39) $\mathrm{NH}_{2}$ infusion was significantly greater in the acarbose treatment period than in the placebo treatment period $(119 \pm 116 \%$ vs $39 \pm 27 \%, P=0.0163)$.

\section{GLP-1 and GIP}

During the acarbose and placebo treatment periods, no difference was observed in fasting plasma GLP-1 levels $(P=0.1212)$ (Fig. 3A and Table 2$)$. In the placebo period, both postprandial peak GLP-1 concentrations $(P=0.003)$ and bsAUCs for GLP-1 $(P<0.0001)$ were higher during exendin(9-39) $\mathrm{NH}_{2}$ infusions compared to saline. In the acarbose period, postprandial GLP-1 levels were significantly higher than in the placebo period (Fig. 3A, B and Table 2). Fasting plasma GIP levels were similar on all four study days (Fig. 3C and Table 2), and exendin(9-39) $\mathrm{NH}_{2}$ infusion did not affect the postprandial plasma GIP levels in any of the treatment periods. As expected, in the acarbose treatment period, postprandial GIP responses were significantly lower than in the placebo period $(P<0.001)$ (Fig. 3C, D and Table 2).

\section{Gastric emptying}

Compared to placebo treatment, treatment with acarbose decreased peak concentration of plasma paracetamol (0.100 vs $0.116 \mathrm{mmol} / \mathrm{L}, P=0.0124)$ and delayed the time to peak concentration of plasma paracetamol $(95 \pm 44$ vs $120 \pm 47 \mathrm{~min}, P=0.0395$ ) during saline infusions (Fig. $4 \mathrm{~A}$ and $\mathrm{B})$. Furthermore, compared to saline infusion, exendin(9-39) $\mathrm{NH}_{2}$ shortened time to peak of paracetamol in plasma in both treatment periods, however only significantly during placebo treatment $(P=0.0275)$.

\section{Insulin, C-peptide, C-peptide: glucose ratios and glucagon}

No significant differences in baseline values of insulin, C-peptide, C-peptide:glucose ratios or glucagon were observed (Fig. 5A, C, E, G and Table 2). Compared to placebo, acarbose treatment diminished bsAUC for insulin significantly during saline $(26 \pm 16$ vs $15 \pm 8.4$ $\mathrm{nmol} / \mathrm{L} \min )(P=0.0038)$ as well as exendin(9-39) $\mathrm{NH}_{2}$ 
Table 2 Overview of plasma and serum measurements. Overview of plasma and serum measurements from the four liquid mixed meal tests (with concommitant i.v. exendin(9-39) $\mathrm{NH}_{2}$ infusion and saline infusion, respectively) performed during the two 14-day treatment periods (placebo treatment and acarbose treatment, respectively). Data are presented as mean \pm S.D.

Differences between groups were compared with rmANOVA with Greenhouse-Geisser correction and Tukey multiple comparison.

\begin{tabular}{|c|c|c|c|c|c|}
\hline & \multicolumn{2}{|c|}{ Placebo treatment } & \multicolumn{2}{|c|}{ Acarbose treatment } & \multirow[b]{2}{*}{$P$ value rmANOVA } \\
\hline & + saline* & $+\operatorname{ex}(9-39) \mathrm{NH}_{2}^{\dagger}$ & + saline $^{\ddagger}$ & $+\operatorname{ex}(9-39) \mathrm{NH}_{2}^{5}$ & \\
\hline \multicolumn{6}{|l|}{ Glucose } \\
\hline Baseline (mmol/L) & $7.8 \pm 1.9$ & $8.1 \pm 1.8$ & $7.5 \pm 1.7$ & $7.7 \pm 1.7$ & 0.13 \\
\hline Peak (mmol/L) & $12 \pm 2.1^{\dagger \neq \S}$ & $14 \pm 2.4^{\star \star \S}$ & $9.3 \pm 1.9 *+\S$ & $11 \pm 1.9^{\star \star \ddagger}$ & $<0.0001$ \\
\hline Time to peak (min) & $87 \pm 20$ & $74 \pm 14^{\S}$ & $89 \pm 30$ & $97 \pm 21^{\dagger}$ & 0.019 \\
\hline bsAUC (mmol/L $\times$ min) & $470 \pm 128^{t \ddagger}$ & $650 \pm 200^{\star \star \S}$ & $214 \pm 98 *+\S$ & $395 \pm 115^{\dagger \ddagger}$ & $<0.0001$ \\
\hline \multicolumn{6}{|l|}{ GLP-1 } \\
\hline Baseline (pmol/L) & $18 \pm 3.2$ & $18 \pm 3.9$ & $21 \pm 4.4$ & $20 \pm 4.4$ & 0.12 \\
\hline Peak (pmol/L) & $30 \pm 5.4^{\dagger \neq \S}$ & $46 \pm 13^{* \S}$ & $40 \pm 8.8^{* \S}$ & $65 \pm 16^{* t \ddagger}$ & $<0.0001$ \\
\hline Time to peak (min) & $61 \pm 41$ & $61 \pm 39$ & $61 \pm 59$ & $83 \pm 53$ & 0.38 \\
\hline bsAUC (pmol/L $\times \min )$ & $1421 \pm 709^{\dagger \downarrow \S}$ & $2537 \pm 1444^{* \S}$ & $2657 \pm 655^{\star \S}$ & $5150 \pm 1835 * t \ddagger$ & $<0.0001$ \\
\hline \multicolumn{6}{|l|}{ GIP } \\
\hline Baseline (pmol/L) & $9.7 \pm 3.4$ & $11 \pm 3.2$ & $12 \pm 4.8$ & $12 \pm 6.8$ & 0.36 \\
\hline Peak (pmol/L) & $72 \pm 19^{\dagger \ddagger \S}$ & $92 \pm 28^{\star \star \S}$ & $45 \pm 13^{* \dagger}$ & $46 \pm 16^{* \dagger}$ & $<0.0001$ \\
\hline Time to peak (min) & $56 \pm 25$ & $47 \pm 12$ & $60 \pm 55$ & $61 \pm 52$ & 0.61 \\
\hline bsAUC (pmol/L $\times$ min) & $6571 \pm 1727^{\ddagger \S}$ & $7071 \pm 2152^{\ddagger \S}$ & $3351 \pm 1943^{* \dagger}$ & $3899 \pm 1123^{* \dagger}$ & $<0.0001$ \\
\hline \multicolumn{6}{|l|}{ Insulin } \\
\hline Baseline (pmol/L) & $76 \pm 52$ & $80 \pm 46$ & $82 \pm 53$ & $75.13 \pm 41$ & 0.77 \\
\hline Peak (pmol/) & $283 \pm 176$ & $304 \pm 186$ & $184 \pm 81$ & $181 \pm 96$ & 0.015 \\
\hline Time to peak (min) & $78 \pm 30$ & $64 \pm 25$ & $62 \pm 34$ & $83 \pm 53$ & 0.3 \\
\hline bsAUC (nmol/L $\times$ min) & $26 \pm 16^{\ddagger \S}$ & $28 \pm 18^{\ddagger \S}$ & $15 \pm 8.4^{* \dagger}$ & $18 \pm 11 * t$ & $<0.0001$ \\
\hline \multicolumn{6}{|l|}{ C-peptide } \\
\hline Baseline (pmol/L) & $884 \pm 413$ & $961 \pm 431$ & $914 \pm 405$ & $862 \pm 331$ & 0.26 \\
\hline Peak (pmolL) & $2,031 \pm 803^{\ddagger \S}$ & $1,948 \pm 763^{\ddagger \S}$ & $1,552 \pm 613^{\dagger}$ & $1,534 \pm 700^{\dagger}$ & $<0.0001$ \\
\hline Time to peak (min) & $111 \pm 37^{\ddagger}$ & $110 \pm 26^{\ddagger \S}$ & $146 \pm 55^{* \dagger}$ & $141 \pm 46^{*}$ & 0.0026 \\
\hline bsAUC (nmol/L × min) & $178 \pm 81^{\neq \S}$ & $170 \pm 97^{\ddagger \S}$ & $109 \pm 57^{* \dagger}$ & $116 \pm 63^{* \dagger}$ & $<0.0001$ \\
\hline \multicolumn{6}{|l|}{ C-peptide:glucose ratio } \\
\hline Baseline (pmol/mmol) & $117 \pm 51$ & $123 \pm 55$ & $126 \pm 60$ & $117 \pm 51$ & 0.29 \\
\hline Peak (pmol/mmol) & $222 \pm 105^{\dagger \S}$ & $184 \pm 95^{*}$ & $202 \pm 94$ & $172 \pm 91 *$ & 0.0002 \\
\hline Time to peak (min) & $171 \pm 59$ & $166 \pm 61$ & $192 \pm 45$ & $166 \pm 55$ & 0.34 \\
\hline bsAUC $\left(\mathrm{nmol} / \mathrm{mmol} \times \mathrm{L}^{-1} \mathrm{~min}\right)$ & $15 \pm 9.7^{\dagger \ddagger \S}$ & $12 \pm 9.8^{*}$ & $12 \pm 7.8^{*}$ & $9.5 \pm 7.6^{*}$ & $<0.0001$ \\
\hline \multicolumn{6}{|l|}{ Glucagon } \\
\hline Baseline (pmol/L) & $15 \pm 4.7$ & $17 \pm 6.4$ & $16 \pm 7.8$ & $15 \pm 6.1$ & 0.23 \\
\hline Peak (pmol/L) & $27 \pm 8.5^{\dagger \S}$ & $40 \pm 13^{*}$ & $28 \pm 11 * \S$ & $44 \pm 11^{\ddagger}$ & $<0.0001$ \\
\hline Time to peak (min) & $41 \pm 14^{\S}$ & $57 \pm 36$ & $50 \pm 53$ & $85 \pm 52 *$ & 0.074 \\
\hline bsAUC (pmol/L $\times$ min) & $639 \pm 419^{\dagger \S}$ & $1361 \pm 806 * \S$ & $958 \pm 874^{\S}$ & $2751 \pm 1317^{\star \dagger \ddagger}$ & $<0.0001$ \\
\hline \multicolumn{6}{|l|}{ PYY } \\
\hline Baseline (pmol/L) & $21 \pm 8$ & $23 \pm 9$ & $27 \pm 10$ & $23 \pm 10$ & 0.22 \\
\hline Peak (pmol/L) & $35 \pm 11^{\dagger \S}$ & $48 \pm 12^{*}$ & $38 \pm 8^{\S}$ & $60 \pm 16^{* \ddagger}$ & 0.0001 \\
\hline Time to peak (min) & $84 \pm 64$ & $97 \pm 51$ & $96 \pm 47$ & $118 \pm 57$ & 0.34 \\
\hline bsAUC (pmol/L $\times$ min $)$ & $1771 \pm 1545^{\S}$ & $3431 \pm 2530$ & $1956 \pm 1264^{\S}$ & $5531 \pm 2276^{\ddagger \star}$ & 0.0001 \\
\hline \multicolumn{6}{|l|}{ Neurotensin } \\
\hline Baseline (pmol/L) & $19 \pm 10$ & $18 \pm 12$ & $23 \pm 11$ & $22 \pm 11$ & 0.37 \\
\hline Peak (pmol/L) & $47 \pm 26^{\S}$ & $62 \pm 27$ & $55 \pm 23^{\S}$ & $85 \pm 39 * \neq$ & 0.0026 \\
\hline Time to peak (min) & $51 \pm 43$ & $65 \pm 44$ & $54 \pm 54$ & $58 \pm 55$ & 0.8 \\
\hline bsAUC (pmol/L $\times$ min) & $2940 \pm 3207$ & $4601 \pm 2875$ & $3373 \pm 2601^{\S}$ & $6366 \pm 4739^{\ddagger}$ & 0.013 \\
\hline \multicolumn{6}{|l|}{ Gastrin } \\
\hline Baseline (pmol/L) & $14 \pm 22$ & $14 \pm 23$ & $19 \pm 34$ & $16 \pm 22$ & 0.68 \\
\hline Peak (pmol/L) & $22 \pm 23$ & $23 \pm 22$ & $22 \pm 30$ & $19 \pm 20$ & 0.65 \\
\hline Time to peak (min) & $58 \pm 56$ & $61 \pm 58$ & $66 \pm 57$ & $48 \pm 56$ & 0.78 \\
\hline bsAUC (pmol/L $\times$ min $)$ & $839 \pm 826$ & $886 \pm 676$ & $555 \pm 477$ & $817 \pm 1134$ & 0.52 \\
\hline \multicolumn{6}{|l|}{ CCK } \\
\hline Baseline (pmol/L) & $1.3 \pm 1.2$ & $1.3 \pm 1.1$ & $1.8 \pm 2.4$ & $1.5 \pm 1.2$ & 0.21 \\
\hline Peak (pmol/L) & $8.8 \pm 4.6$ & $9.0 \pm 4.2$ & $12 \pm 8.3$ & $10 \pm 6.6$ & 0.33 \\
\hline Time to peak (min) & $24 \pm 20$ & $34 \pm 45$ & $22 \pm 14$ & $31 \pm 15$ & 0.45 \\
\hline bsAUC (pmol/L $\times$ min) & $449 \pm 394$ & $397 \pm 431$ & $643 \pm 482$ & $539 \pm 409$ & 0.23 \\
\hline
\end{tabular}

Symbols for $P<0.05$ by Tukey multiple comparison compared with: * placebo treatment + saline; ${ }^{\dagger}$ placebo treatment $+\operatorname{exendin}(9-39) \mathrm{NH}_{2} ;{ }^{\ddagger}$ acarbose treatment + saline; or ${ }^{\S}$ acarbose treatment + exendin(9-39) $\mathrm{NH}_{2}$.

bsAUC, baseline-subtracted AUC; CCK, cholecystokinin; ex(9-39) $\mathrm{NH}_{2}$, exendin(9-39) $\mathrm{NH}_{2}$; GIP, glucose-dependent insulinotropic polypeptide; GLP-1, glucagon-like peptide-1; PYY, peptide tyrosine tyrosine; rmANOVA, repeated measures ANOVA. 

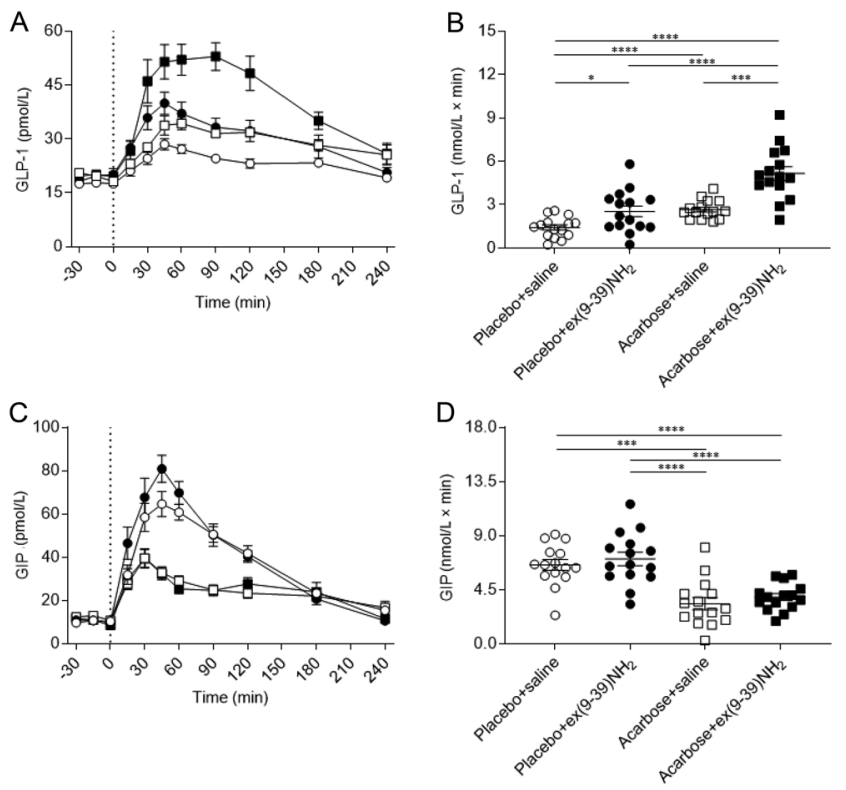

\section{Figure 3}

GLP-1 and GIP. Plasma levels of GLP-1 (A) and GIP (C) and corresponding bsAUC (time 0-240 min) (B and D) during four liquid mixed meal tests (initiated at time 0 , dotted line) with continuous i.v. infusion of exendin(9-39) $\mathrm{NH}_{2}$ (closed symbols) and saline (open symbols), respectively, performed after 14-day treatment periods with placebo (circles) and acarbose (squares). Data were compared by rmANOVA with Greenhouse-Geisser correction and Tukey multiple comparison. Significant differences for the post hoc analyses are marked with asterisks: $* P<0.05 ; * \star \star P<0.001 ; * \star \star \star P<<$ 0.0001. Data are presented as mean \pm S.E.M. $\operatorname{ex}(9-39) \mathrm{NH}_{2}$, exendin(9-39) $\mathrm{NH}_{2}$.

infusion $(28 \pm 18$ vs $18 \pm 11 \mathrm{nmol} / \mathrm{L} \min )(P=0.0012)$ (Fig. 5A, B and Table 2). We observed no difference in insulin responses between the two infusions (with and without exendin(9-39) $\mathrm{NH}_{2}$ ) during acarbose treament $(P=0.1860)$ or during placebo treament $(P=0.4537)$. Similar results were observed for C-peptide (Fig. 5C, D and Table 2). Postprandial C-peptide:glucose ratios were generally higher in the placebo period compared to the acarbose period (Fig. 5E, F and Table 2); however, only significantly different during saline infusions $(P=0.0458)$. Compared to saline, exendin(9-39) $\mathrm{NH}_{2}$ infusion reduced C-peptide:glucose ratios $(P=0.0034)$ in the placebo period and tended to do so also in the acarbose period $(P=0.22)$. In each of the two treatment periods, postprandial peak plasma glucagon levels were highest during exendin(9-39) $\mathrm{NH}_{2}$ infusion compared to saline infusion (Fig. 5G and Table 2). Postprandial glucagon responses as assessed by bsAUC were also greater during exendin(9-39) $\mathrm{NH}_{2}$ infusion than during saline infusion in both treatment periods with the greatest responses being observed during exendin(9-39) $\mathrm{NH}_{2}$ infusion in the acarbose treatment period (Fig. $5 \mathrm{H}$ and Table 2).

\section{PYY, neurotensin, ad libitum meal intake, and appetite and satiety measures}

Fasting plasma levels of PYY were similar on all four study days (Fig. 6A and Table 2). Postprandial plasma PYY peak levels were significantly higher during exendin(9-39) $\mathrm{NH}_{2}$ infusion, compared to saline infusion in both treatment periods (Fig. 6A, B and Table 2). Also, postprandial PYY responses (as assessed by bsAUC) were augmented during exendin(9-39) $\mathrm{NH}_{2}$ infusion compared to placebo in both treatment periods, but significantly so only in the acarbose treatment period $(P=0.1319$ and $P<0.0001)$ (Fig. 6A, B and Table 2). No differences were observed between placebo and acarbose treatment with regard to neurotensin; however, levels were generally higher during exendin(9-39) $\mathrm{NH}_{2}$ infusion in the acarbose period (Fig. 6C, D and Table 2). No differences were observed in ad libitum food intake (for saline days in placebo treatment $451 \pm 269 \mathrm{~g}$ vs $343 \pm 176 \mathrm{~g}$ in acarbose periode, $P=0.3642$ ) (Supplementary Fig. 1A, see section on supplementary materials given at the end of this article) or appetite measures assessed by VASs (hunger, satiety, fullness, prospective food consumption, comfort, nausea and thirst) (Supplementary Fig. 2 and Supplementary Table 2).

\section{Gastrin, CCK and gallbladder volume}

We observed no significant differences in gastrin and CCK levels or gallbladder volume when comparing the two treatment periods or when comparing the effects of exendin(9-39) $\mathrm{NH}_{2}$ and saline infusion (Supplementary Figs 3, 4 and Supplementary Table 2).

\section{Discussion}

We confirm that acarbose improves postprandial glucose tolerance compared to placebo; shows acarbose-induced doubling of postprandial GLP-1 responses; using the GLP-1 receptor antagonist exendin(9-39) $\mathrm{NH}_{2}$, we did not see an impact of acarbose-induced GLP-1 secretion on absolute measures of postprandial glucose tolerance, 

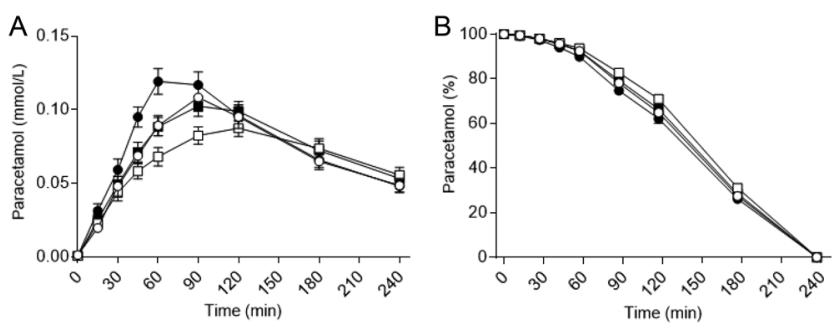

Figure 4

Gastric emptying assessed by paracetamol. Plasma

paracetamol levels (A) and corresponding gastric emptying (B) in minutes after intake of paracetamol with liquid mixed meal expressed as mean percentage of the meal retained in stomach (time 0-240 min) during four liquid mixed meal tests (time 0 to $240 \mathrm{~min}$ ) with continuous i.v. infusion of exendin(9-39) $\mathrm{NH}_{2}$ (closed symbols) and saline (open symbols), respectively, performed after 14-day treatment periods with placebo (circles) and acarbose (squares). Data are presented as mean \pm S.E.M. ex(9-39) $\mathrm{NH}_{2}$, exendin(9-39) $\mathrm{NH}_{2}$.

but relatively, the effect of exendin(9-39) $\mathrm{NH}_{2}$ was most pronounced during acarbose.

\section{Alpha-glucosidase inhibition induces GLP-1 secretion}

Our data confirm that acarbose-induced transfer of polysaccharides to the more distal parts of the small intestine affects several of the gut hormones including GLP-1 $(6,8,10)$. In our design, acarbose treatment for 14 days almost doubled the postprandial GLP-1 response after liquid mixed meal intake both during saline and exendin(9-39) $\mathrm{NH}_{2}$ infusion, compared to placebo. The effect of acarbose on GLP-1 secretion has been investigated quite extensively with differing results. Some single-dose studies or studies investigating shorter acarbose treatment courses have not been able to measure an effect of acarbose on GLP-1 secretion $(9,24,25,26)$. The effect of acarbose could depend on longer treatment as illustrated by the present study, and a study by Zheng et al. who observed higher levels of both fasting and postprandial GLP-1 during a solid mixed meal test after 24 weeks of acarbose treatment in drug-naïve individuals with prediabetes (11). In addition, the dose of acarbose seems to constitute an important determinant of GLP-1 secretion; when comparing 25, 50 and $100 \mathrm{mg}$ single-doses, only the 100 mg dose significantly increased GLP-1 levels during solid
A

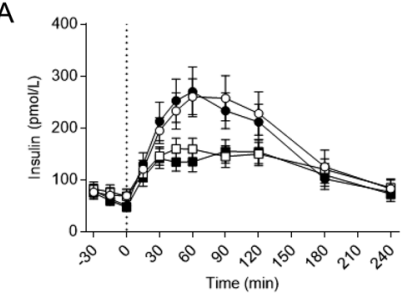

C
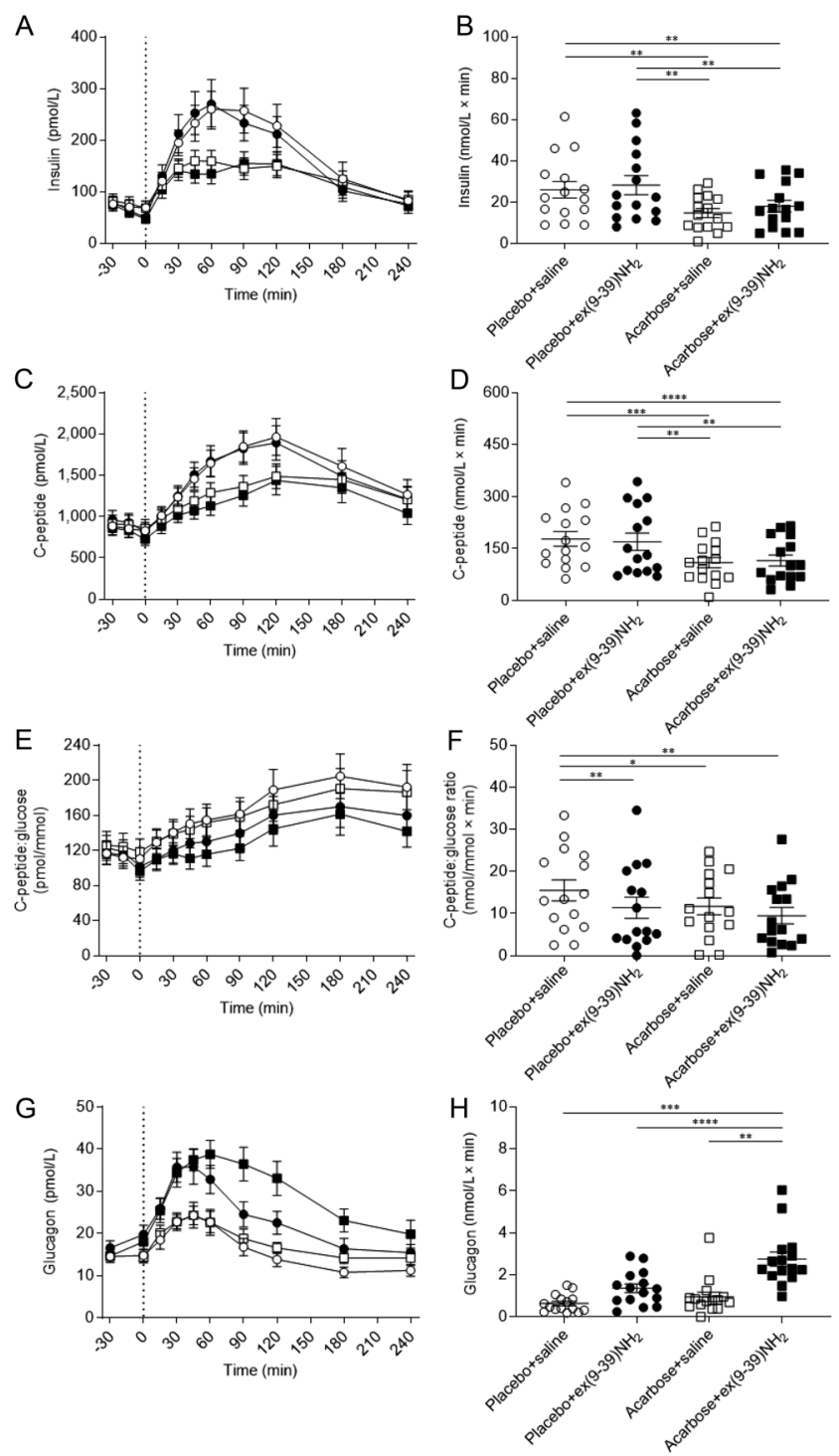

Figure 5

Insulin, C-peptide, C-peptide:glucose ratio and glucagon. Plasma levels of insulin (A), C-peptide (C), C-peptide:glucose ratio $(E)$ and glucagon $(G)$ and corresponding bsAUC (time 0-240 min) ( $B, D, F$ and $H$ ) during four liquid mixed meal tests (initiated at time 0 , dotted line) with continuous i.v. infusion of exendin(9-39) $\mathrm{NH}_{2}$ (closed symbols) and saline (open symbols), respectively, performed after 14-day treatment periods with placebo (circles) and acarbose (squares). Data were compared by rmANOVA with Greenhouse-Geisser correction and Tukey multiple comparison. Significant differences for the post hoc analyses are marked with asterisks: ${ }^{*} P<0.05$; $* * P<0.01$; $\star * * P<0.001 ; * * * * P<0.0001$. Data are presented as mean \pm S.E.M. ex(9-39) $\mathrm{NH}_{2}$, exendin(9-39) $\mathrm{NH}_{2}$. 

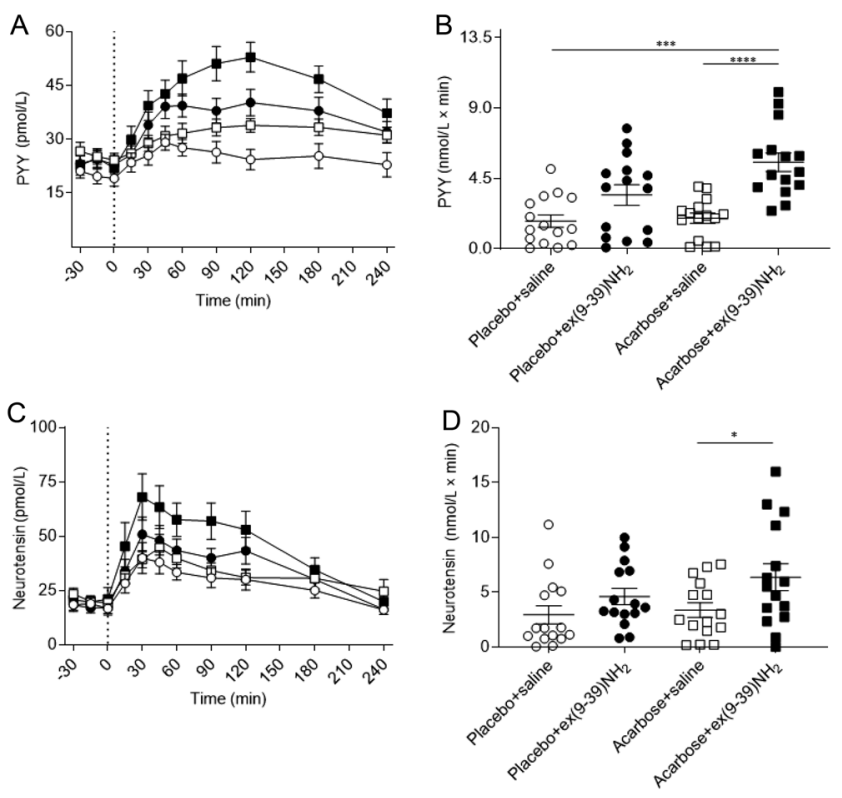

\section{Figure 6}

PYY and neurotensin. Plasma levels of PYY (A) and neurotensin (C) and corresponding bsAUC (time 0-240 min) (B and D) during four liquid mixed meal tests (initiated at time 0 , dotted line) with continuous i.v. infusion of exendin(9-39) $\mathrm{NH}_{2}$ (closed symbols) and saline (open symbols), respectively, performed after 14-day treatment periods with placebo (circles) and acarbose (squares). Data were compared by rmANOVA with Greenhouse-Geisser correction and Tukey multiple comparison. Significant differences for the post hoc analyses are marked with asterisks: ${ }^{*} P<0.05 ; * \star * P<0.001$; $* \star \star * P<$ 0.0001. Data are presented as mean \pm S.E.M. $\operatorname{ex}(9-39) \mathrm{NH}_{2}$, exendin(9-39) $\mathrm{NH}_{2}$.

mixed meal ingestion $(25,27)$. Another factor affecting acarbose-induced GLP-1 secretion seems to be the diet composition. A single dose of $100 \mathrm{mg}$ acarbose during an oral sucrose (disaccharide) load resulted in elevated GLP-1 levels compared to placebo $(8,10,28,29)$ whereas no effect was seen during oral glucose tolerance test (24), emphasizing that acarbose needs relevant carbohydrates to 'act on' in order to increase GLP-1 secretion (24). In line with this notion, the glucose-lowering efficacy of acarbose has been shown to depend on the amount of polysaccharides/starch in the diet (30). In this study, we used a liquid mixed meal test with $49 \%$ polysaccharides (primarly maltodextrin); thus one could speculate that our estimate is conservative compared to what could be expected from a solid meal meal with a greater content of polysaccharides and fibers (12). Taken together, longer treatment periods with maximum dosing of acarbose and a high amount of starch and fibers in the diet seem important for the GLP-1-inducing action of acarbose.

\section{Alpha-glucosidase inhibition improves glucose metabolism}

Acarbose treatment is generally thought to reduce postprandial hyperglycemia by inhibiting carbohydrate hydrolysis, and, thus, retarding and inhibiting glucose absorption. In order to delineate whether acarboseinduced GLP-1 secretion contributes to the glucoselowering effect of acarbose during a meal, we investigated the effect of acarbose on postprandial glucose excursions with and without blockade of the GLP-1 receptor using exendin(9-39) $\mathrm{NH}_{2}$. To our knowledge, no previous studies have utilized exendin(9-39) $\mathrm{NH}_{2}$ to isolate GLP1-mediated effects induced by acarbose. The study was powered to detect a minimal difference of $25 \%$ in plasma glucose excursions during a standardized mixed meal test. This minimal difference was based on the judgment that a $\geq 25 \%$ change in plasma glucose excursions during a standardized mixed meal test is clinically and physiologically relevant. We chose to express the minimal relevant difference in percent (relative difference) as no reference material exist, and because we expected a high degree of inter-individual variation in absolute AUC values for plasma glucose during a standardized mixed meal test in patients with type 2 diabetes. We observed that exendin(9-39) $\mathrm{NH}_{2}$ more than doubled bsAUC for glucose during the mixed meal test in the acarbose treatment period (a 119\% increase) - significantly more than the exendin(9-39) $\mathrm{NH}_{2}$-induced increase in bsAUC of $39 \%$ during the placebo treatment period. In absolute terms, nevertheless, exendin(9-39) $\mathrm{NH}_{2}$ affected postprandial glucose tolerance (as assessed by bsAUC) similarly during the acarbose and placebo treatment periods. Using exendin(9-39) $\mathrm{NH}_{2}$, we were not able to show a greater GLP-1-mediated insulin secretion or beta cell sensitivity to glucose during the acarbose treatment period. Whether this relates to the much smaller postprandial glucose excursions and insulin secretory responses during acarbose treatment or the well-known compensatory rise in postprandial glucagon levels during exendin(9-39) $\mathrm{NH}_{2}$ infusions (which in the present study was highest during the acarbose treatment period), or other factors, is uncertain. Similar observations have been made previously in studies using exendin $(9-39) \mathrm{NH}_{2}$, and together these observations indicate that results obtained with exendin(9-39) $\mathrm{NH}_{2}$ regarding beta cell function in vivo should be interpreted with care (31). Specifically, 
the markedly increased glucagon secretion may be responsible for a considerable paracrine stimulation of insulin secretion via the unblocked glucagon receptors (presumably due to inhibition of GLP-1-mediated effects in the pancreatic islets) (32).

\section{Alpha-glucosidase inhibition does not affect CCK and gallbladder volume}

Acarbose has previously been shown to increase CCK secretion $(12,33)$, and we have previously demonstrated that CCK-induced gallbladder emptying stimulates GLP-1 secretion $(34,35)$. In the present study we found no difference in CCK release or gallbladder emptying between treatment periods and, thus, no indications that acarbose-induced GLP-1 secretion involves augmented CCK secretion and gallbladder emptying.

\section{Alpha-glucosidase inhibition delays gastric emptying and results in lower GIP levels}

Our study confirms previous findings that acarbose delays gastric emptying $(12,28)$. When we inhibited GLP-1 receptor signaling with exendin(9-39) $\mathrm{NH}_{2}$, gastric emptying of the liquid meal was equally accelerated in both treatment periods, and, thus, acarbose-induced deceleration of gastric emptying does not seem to rely - at least not entirely - on acarbose-induced GLP-1 secretion. As previously reported (24), postprandial GIP levels were diminished by acarbose treatment, consistent with the notion that most enteroendocrine GIP-secreting $\mathrm{K}$ cells are located in the duodenum and proximal jejunum, which during acarbose treatment absorb less glucose than under normal circumstances (2). Acarbose-induced deceleration of gastric emptying may also contribute to the lower postprandial GIP response observed in the acarbose treatment period.

\section{Alpha-glucosidase inhibition does not affect appetite sensations or ad libitum food intake}

It has been shown that release of GLP-1 in combination with the other L cell product PYY exerts a satietypromoting effect (36). In contrast to previous studies $(12,37)$, the potentiation of the postprandial PYY response during acarbose treatment was not statistically significant. In line with this, we were not able to detect any significant changes in appetite sensations or food intake ad libitum with acarbose treatment. However, the power of our study with regard to these exploratory endpoints is inadequate to rule out potentially relevant differences.

\section{Limitations}

Despite rejection of the null hypothesis, we cannot rule out that with a larger sample size, differences in secondary endpoints, for example, postprandial plasma responses of PYY and neurotensin, could have been detected. The liquid mixed meals were identical and standardized, and throughout both treatment periods, the study participants were instructed to continue their usual diets. However, food intake was not logged (neither qualitatively or quantitatively), and it is possible that irregular diets or varying content of carbohydrates could have influenced the postprandial glucose excursions in this study. We used a crossover design and randomisation of treatment sequences to minimize these potential biases.

\section{Conclusion}

We confirm that acarbose treatment stimulates postprandial GLP-1 secretion in patients with type 2 diabetes. Using exendin(9-39) $\mathrm{NH}_{2}$, we did not see an impact of acarbose-induced GLP-1 secretion on absolute measures of postprandial glucose tolerance, but relatively, the effect of exendin(9-39) $\mathrm{NH}_{2}$ was most pronounced during acarbose treatment.

Supplementary materials

This is linked to the online version of the paper at https://doi.org/10.1530/ EJE-20-1121.

\section{Declaration of interest}

$\mathrm{J} \mathrm{J} H$ serves on advisory boards for Novo Nordisk. T $\mathrm{V}$ has served on scientific advisory panels, been part of speaker's bureaus for, served as a consultant to and/or received research support from Amgen, AstraZeneca, Boehringer Ingelheim, Eli Lilly, Gilead, Mundipharma, MSD/Merck, Novo Nordisk, Sanofi and Sun Pharma. F K K has served on scientific advisory panels and/or been part of speaker's bureaus for, served as a consultant to and/or received research support from Amgen, AstraZeneca, Bayer, Boehringer Ingelheim, Carmot Therapeutics, Eli Lilly, Gubra, Medlmmune, MSD/Merck, Mundipharma, Norgine, Novo Nordisk, Sanofi and Zealand Pharma. Filip K Knop is on the editorial board of EJE. Filip K Knop was not involved in the review or editorial process for this paper, on which he/she is listed as an author. The other authors have nothing to disclose.

\section{Funding}

The clinical study was conducted at Center for Clinical Metabolic Research, Gentofte Hospital, University of Copenhagen, Hellerup, Denmark and supported by Herlev-Gentofte Hospital's Research Council; the A.P. Møller 
Foundation 'Lægefonden'; the NovoNordisk Foundation and Eva og Hans Carl Adolf Holms Mindelegat.

\section{Guarantor statement}

All authors agreed to be accountable for all aspects of the work in ensuring that questions related to the accuracy or integrity of any part of the work are appropriately investigated and resolved.

\section{Author contribution statement}

N B D, L S H and N L H performed the study. B H, S S and L S G performed the biochemical analysis. N B D, LS G and F K K designed the study and wrote the study protocol. $\mathrm{F} \mathrm{K} \mathrm{K}$ conceptualized and academically supervised the study. J J H, J F R and B H generated data. N B D, L S G and F K K drafted the manuscript. All authors contributed substantially to the acquisition, analysis or interpretation of data for the work, critically revised the manuscript for important intellectual content, and approved the final version.

\section{Acknowledgements}

The authors are grateful for the commitment from the study participants. The authors thank Sisse Marie Schmidt and Inass Al Nachar (Center for Clinical Metabolic Research, Gentofte Hospital, University of Copenhagen, Denmark) and Lene Albæk (Department of Biomedical Sciences, University of Copenhagen, Denmark) for laboratory assistance. Parts of the study were presented in abstract form at the 79th Scientific Sessions of the American Diabetes Association (2019)

\section{References}

1 Nauck MA \& Meier JJ. Incretin hormones: their role in health and disease. Diabetes, Obesity and Metabolism 201820 (Supplement 1) 5-21. (https://doi.org/10.1111/dom.13129)

2 Jorsal T, Rhee NA, Pedersen J, Wahlgren CD, Mortensen B, Jepsen SL, Jelsing J, Dalboge LS, Vilmann P, Hassan $\mathrm{H}$ et al. Enteroendocrine $\mathrm{K}$ and L cells in healthy and type 2 diabetic individuals. Diabetologia 201861 284-294. (https://doi.org/10.1007/s00125-017-4450-9)

3 Gasbjerg LS, Helsted MM, Hartmann B, Sparre-Ulrich AH, Veedfald S, Stensen S, Lanng AR, Bergmann NC, Christensen MB, Vilsbøll T et al. GIP and GLP-1 Receptor Antagonism During a Meal in Healthy Individuals. Journal of Clinical Endocrinology \& Metabolism 2020105 e725-e738. (https://doi.org/10.1210/clinem/dgz175)

4 Kreymann B, Williams G, Ghatei MA \& Bloom SR. Glucagon-like peptide-1 7-36: a physiological incretin in man. Lancet 19872 1300-1304. (https://doi.org/10.1016/s0140-6736(87)91194-9)

5 Secher A, Jelsing J, Baquero AF, Hecksher-Sorensen J, Cowley MA, Dalboge LS, Hansen G, Grove KL, Pyke C, Raun K et al. The arcuate nucleus mediates GLP-1 receptor agonist liraglutide-dependent weight loss. Journal of Clinical Investigation 2014124 4473-4488. (https://doi.org/10.1172/JCI75276)

6 Kuhre RE, Christiansen CB, Saltiel MY, Wewer Albrechtsen NJ $\&$ Holst JJ. On the relationship between glucose absorption and glucose-stimulated secretion of GLP-1, neurotensin, and PYY from different intestinal segments in the rat. Physiological Reports 20175 e13507. (https://doi.org/10.14814/phy2.13507)

7 Joshi SR, Standl E, Tong N, Shah P, Kalra S \& Rathod R. Therapeutic potential of alpha-glucosidase inhibitors in type 2 diabetes mellitus: an evidence-based review. Expert Opinion on Pharmacotherapy 201516 1959-1981. (https://doi.org/10.1517/14656566.2015.1070827)

8 Qualmann C, Nauck MA, Holst JJ, Orskov C \& Creutzfeldt W. Glucagon-like peptide 1 (7-36 amide) secretion in response to luminal sucrose from the upper and lower gut. A study using alpha-glucosidase inhibition (acarbose). Scandinavian
Journal of Gastroenterology 199530 892-896. (https://doi. org/10.3109/00365529509101597)

9 Hucking K, Kostic Z, Pox C, Ritzel R, Holst JJ, Schmiegel W \& Nauck MA. Alpha-glucosidase inhibition (acarbose) fails to enhance secretion of glucagon-like peptide 1 (7-36 amide) and to delay gastric emptying in Type 2 diabetic patients. Diabetic Medicine 200522 470-476. (https://doi.org/10.1111/j.1464-5491.2005.01451.x)

10 Seifarth C, Bergmann J, Holst JJ, Ritzel R, Schmiegel W \& Nauck MA. Prolonged and enhanced secretion of glucagon-like peptide 1 (7-36 amide) after oral sucrose due to alpha-glucosidase inhibition (acarbose) in Type 2 diabetic patients. Diabetic Medicine 199815 485-491. (https://doi.org/10.1002/(SICI)10969136(199806)15:6<485::AID-DIA610>3.0.CO;2-Y)

11 Zheng MY, Yang JH, Shan CY, Zhou HT, Xu YG, Wang Y, Ren HZ, Chang BC \& Chen LM. Effects of 24-week treatment with acarbose on glucagon-like peptide 1 in newly diagnosed type 2 diabetic patients: a preliminary report. Cardiovascular Diabetology 20131273. (https://doi.org/10.1186/1475-2840-12-73)

12 Enc FY, Imeryuz N, Akin L, Turoglu T, Dede F, Haklar G, Tekesin N, Bekiroglu N, Yegen BC, Rehfeld JF et al. Inhibition of gastric emptying by acarbose is correlated with GLP-1 response and accompanied by CCK release. American Journal of Physiology: Gastrointestinal and Liver Physiology 2001281 G752-G763. (https:// doi.org/10.1152/ajpgi.2001.281.3.G752)

13 Ueno H, Tsuchimochi W, Wang HW, Yamashita E, Tsubouchi C, Nagamine K, Sakoda H \& Nakazato M. Effects of miglitol, acarbose, and sitagliptin on plasma insulin and gut peptides in type 2 diabetes mellitus: a crossover study. Diabetes Therapy 20156 187-196. (https://doi.org/10.1007/s13300-015-0113-3)

14 Dodds WJ, Groh WJ, Darweesh RM, Lawson TL, Kishk SM \& Kern MK. Sonographic measurement of gallbladder volume. American Journal of Roentgenology 1985145 1009-1011. (https://doi. org/10.2214/ajr.145.5.1009)

15 Orskov C, Rabenhoj L, Wettergren A, Kofod H \& Holst JJ. Tissue and plasma concentrations of amidated and glycine-extended glucagonlike peptide I in humans. Diabetes 199443 535-539. (https://doi. org/10.2337/diab.43.4.535)

16 Lindgren O, Carr RD, Deacon CF, Holst JJ, Pacini G, Mari A \& Ahren B. Incretin hormone and insulin responses to oral versus intravenous lipid administration in humans. Journal of Clinical Endocrinology and Metabolism 201196 2519-2524. (https://doi. org/10.1210/jc.2011-0266)

17 Toräng S, Bojsen-Møller KN, Svane MS, Hartmann B, Rosenkilde MM, Madsbad S \& Holst JJ. In vivo and in vitro degradation of peptide YY3-36 to inactive peptide YY3-34 in humans. American Journal of Physiology: Regulatory, Integrative and Comparative Physiology 2016310 R866-R874. (https://doi.org/10.1152/ajpregu.00394.2015)

18 Kuhre RE, Bechmann LE, Wewer Albrechtsen NJ, Hartmann B \& Holst JJ. Glucose stimulates neurotensin secretion from the rat small intestine by mechanisms involving SGLT1 and GLUT2, leading to cell depolarization and calcium influx. American Journal of Physiology: Endocrinology and Metabolism 2015308 E1123-E1130. (https://doi. org/10.1152/ajpendo.00012.2015)

19 Jorgensen NB, Dirksen C, Bojsen-Moller KN, Jacobsen SH, Worm D, Hansen DL, Kristiansen VB, Naver L, Madsbad S \& Holst JJ. Exaggerated glucagon-like peptide 1 response is important for improved beta-cell function and glucose tolerance after Roux-en-Y gastric bypass in patients with type 2 diabetes. Diabetes 201362 3044-3052. (https://doi.org/10.2337/db13-0022)

20 Rehfeld JF. Accurate measurement of cholecystokinin in plasma. Clinical Chemistry 199844 991-1001. (https://doi.org/10.1093/ clinchem/44.5.991)

21 Stadil F \& Rehfeld JF. Determination of gastrin in serum. An evaluation of the reliability of a radioimmunoassay. Scandinavian Journal of Gastroenterology 19738 101-112. (https://doi.org/10.1080/0 0365521.1973.12096677) 
22 Bahne E, Sun EWL, Young RL, Hansen M, Sonne DP, Hansen JS, Rohde U, Liou AP, Jackson ML, de Fontgalland D et al. Metformininduced glucagon-like peptide-1 secretion contributes to the actions of metformin in type 2 diabetes. JCI Insight 20183 e93936. (https:// doi.org/10.1172/jci.insight.93936)

23 Medhus AW, Lofthus CM, Bredesen J \& Husebye E. Gastric emptying: the validity of the paracetamol absorption test adjusted for individual pharmacokinetics. Neurogastroenterology and Motility 2001 13 179-185. (https://doi.org/10.1046/j.1365-2982.2001.00249.x)

24 Chen Z, Fu X, Kuang J, Chen J, Chen H, Pei J \& Yang H. Single-dose acarbose decreased glucose-dependent insulinotropic peptide and glucagon levels in Chinese patients with newly diagnosed type 2 diabetes mellitus after a mixed meal. BMC Endocrine Disorders 2016 16 55. (https://doi.org/10.1186/s12902-016-0133-7)

25 DeLeon MJ, Chandurkar V, Albert SG \& Mooradian AD. Glucagonlike peptide- 1 response to acarbose in elderly type 2 diabetic subjects. Diabetes Research and Clinical Practice 200256 101-106. (https://doi. org/10.1016/s0168-8227(01)00359-x)

26 Martinussen C, Bojsen-Moller KN, Dirksen C, Svane MS, Kristiansen VB, Hartmann B, Holst JJ \& Madsbad S. Augmented GLP-1 secretion as seen after gastric bypass may be obtained by delaying carbohydrate digestion. Journal of Clinical Endocrinology and Metabolism 2019104 3233-3244. (https://doi.org/10.1210/jc.201802661)

27 Gentilcore D, Bryant B, Wishart JM, Morris HA, Horowitz M $\&$ Jones KL. Acarbose attenuates the hypotensive response to sucrose and slows gastric emptying in the elderly. American Journal of Medicine 2005118 1289. (https://doi.org/10.1016/j. amjmed.2005.05.019)

28 Ranganath L, Norris F, Morgan L, Wright J \& Marks V. Delayed gastric emptying occurs following acarbose administration and is a further mechanism for its anti-hyperglycaemic effect. Diabetic Medicine 199815 120-124. (https://doi.org/10.1002/(SICI)10969136(199802)15:2<120::AID-DIA529>3.0.CO;2-I)

29 Sakurai K, Lee EY, Morita A, Kimura S, Kawamura H, Kasamatsu A, Shiiba M, Yabe D, Yokote K \& Miki T. Glucagon-like peptide-1 secretion by direct stimulation of $\mathrm{L}$ cells with luminal sugar $v s$ nonnutritive sweetener. Journal of Diabetes Investigation 20123 156-163. (https://doi.org/10.1111/j.2040-1124.2011.00163.x)
30 Weng J, Soegondo S, Schnell O, Sheu WH, Grzeszczak W, Watada H, Yamamoto N \& Kalra S. Efficacy of acarbose in different geographical regions of the world: analysis of a real-life database. Diabetes/Metabolism Research and Reviews 201531 155-167. (https:// doi.org/10.1002/dmrr.2576)

31 Gasbjerg LS, Bergmann NC, Stensen S, Christensen MB, Rosenkilde MM, Holst JJ, Nauck M \& Knop FK. Evaluation of the incretin effect in humans using GIP and GLP-1 receptor antagonists. Peptides 2020125 170183. (https://doi.org/10.1016/j. peptides.2019.170183)

32 de Heer J, Rasmussen C, Coy DH \& Holst JJ. Glucagon-like peptide-1, but not glucose-dependent insulinotropic peptide, inhibits glucagon secretion via somatostatin (receptor subtype 2) in the perfused rat pancreas. Diabetologia 200851 2263-2270. (https://doi.org/10.1007/ s00125-008-1149-y)

33 Takei I, Miyamoto K, Funae O, Ohashi N, Meguro S, Tokui M \& Saruta T. Secretion of GIP in responders to acarbose in obese Type 2(NIDDM) patients. Journal of Diabetes and its Complications 200115 245-249. (https://doi.org/10.1016/s1056-8727(01)00148-9)

34 Rohde U, Sonne DP, Christensen M, Hansen M, Bronden A, Torang S, Rehfeld JF, Holst JJ, Vilsboll T \& Knop FK. Cholecystokinin-induced gallbladder emptying and metformin elicit additive glucagon-like peptide-1 responses. Journal of Clinical Endocrinology and Metabolism 2016101 2076-2083. (https://doi.org/10.1210/jc.2016-1133)

35 Bronden A, Alber A, Rohde U, Rehfeld JF, Holst JJ, Vilsboll T \& Knop FK. Single-dose metformin enhances bile acid-induced glucagon-like Peptide-1 secretion in patients with Type 2 diabetes. Journal of Clinical Endocrinology and Metabolism 2017102 4153-4162. (https://doi.org/10.1210/jc.2017-01091)

36 Svane MS, Jorgensen NB, Bojsen-Moller KN, Dirksen C, Nielsen S, Kristiansen VB, Torang S, Wewer Albrechtsen NJ, Rehfeld JF, Hartmann B et al. Peptide YY and glucagon-like peptide-1 contribute to decreased food intake after Roux-en-Y gastric bypass surgery. International Journal of Obesity 201640 1699-1706. (https://doi. org/10.1038/ijo.2016.121)

37 Fuessl HS, Adrian TE, Uttenthal LO \& Bloom SR. Peptide YY in diabetics treated chronically with an intestinal glucosidase inhibitor. Klinische Wochenschrift 198866 985-989. (https://doi.org/10.1007/ BF01738114)

Received 30 September 2020

Revised version received 11 December 2020

Accepted 12 January 2021 